\title{
Suicide Prevention: Literature Review
}

\author{
Sitti Rahma Soleman ${ }^{1}$, Endrat Kartiko Utomo² \\ ${ }^{1}$ Staff Dosen Program Studi S1 Keperawatan, STIKES Graha Medika Kotamobagu, Sulawesi Utara, Indonesia \\ ${ }^{2}$ Dosen Keperawatan, Universitas Duta Bangsa, Surakarta, Indonesia \\ Alamat Korespondensi: sittirahmasoleman@gmail.com
}

\begin{abstract}
Abstrak
Bunuh diri menjadi salah satu penyebab kematian diseluruh dunia. Bunuh diri merupakan suatu tindakan yang disengaja untuk mengakhiri kehidupan. Terapi farmakologis, psikologis, pendidikan kesehatan, dukungan keluarga dan media diusulkan sebagai tindakan yang efektif untuk mengatasi depresi dan bunuh diri. Namun, pedoman tersebut tidak memiliki cukup bukti untuk mencegah bunuh diri sehingga ini menjadi tantangan tersendiri bagi dunia kesehatan khususnya keperawatan. Tujuan review ini untuk melaporkan hasil penelitian yang berfokus pada intervensi yang dilakukan untuk pencegahan bunuh diri. Metode pencarian artikel yang relevan menggunakan database PubMed, Science Direct dan Search Engine Google Scholar menggunakan kata kunci suicide prevention, suicide intervention, dan suicide therapy. Sembilan artikel masuk dalam tinjauan literature, meliputi berbagai macam tipe intervensi bunuh diri, frekuensi intervensi, dan efek dari pemberian intervensi. Literature review ini mengidentifikasi delapan jenis intervensi yang dapat dilakukan dalam mencegah bunuh diri yaitu ACT, CBT, SAFETY, SOS, ASSIP. Kesimpulannya intervensi ACT, CBT, SAFETY, SOS, ASSIP dapat dilakukan untuk mencegah kejadian bunuh diri, dengan meningkatkan pengetahuan, pendidikan, ketarampilan mengenai bunuh diri dan penyadaran penuh terkait bunuh diri serta keikutsertaan keluarga merupakan pokok dari intervensi yang harus dilakukan guna mencegah bunuh diri.
\end{abstract}

Kata Kunci: Pencegahan bunuh diri, intervensi bunuh diri, terapi bunuh diri

\begin{abstract}
Suicide is one of the leading causes of death worldwide. Suicide is an intentional act to end life. Pharmacological, psychological, health education, family support and the media are proposed as effective measures to treat depression and suicide. However, these guidelines do not have sufficient evidence to prevent suicide so this is a challenge for the world of health, especially nursing. The aim of this review is to report the results of studies that focus on interventions undertaken for suicide prevention. The search method for relevant articles uses the database PubMed, Science Direct and Google Scholar using the keywords suicide prevention, suicide intervention, and suicide therapy. Nine articles were included in the literature review, covering various types of suicide intervention, frequency of intervention, and effects of intervention. This literature review identifies eight types of interventions that can be done to prevent suicide, namely ACT, CBT, SAFETY, SOS, ASSIP. The conclusion is that ACT, CBT, SAFETY, SOS, ASSIP interventions can be done to prevent suicide, by increasing knowledge, education, skills regarding suicide and awareness related to suicide and family participation are the main points of interventions that must be carried out to prevent suicide .
\end{abstract}

Keywords: Prevention of suicide, suicide intervention, suicide therapy 


\section{PENDAHULUAN}

The World Health Organization (WHO) memperkirakan bunuh diri merupakan nomor 13 penyebab kematian diseluruh dunia (Robinson et al., 2016). Secara global sekitar 800.000 meninggal karena bunuh diri, dan prevelensinya dua kali lebih tinggi pada upaya bunuh diri. Bunuh diri merupakan penyebab kematian ketiga pada usia 15-19 tahun (World Health Organization, 2019).

Di Indonesia kejadian bunuh diri sebesar 875 kasus pada tahun 2016 dan 789 kasus pada tahun 2017. Sebesar 23,2\% kematian bunuh diri terjadi pada orang dengan gangguan jiwa (Pusat Data dan Informasi Kementrian Kesehatan Republik Indonesia, 2019)

Bunuh diri adalah suatu tindakan yang disengaja untuk mengakhiri kehidupan, bunuh diri juga merupakan permasalahan sosial dimana terjadi ketidaksesuaian di dalam norma masyarakat dan agama (Mulyani \& Eridiana, 2019). Dua kasus yang sering terjadi di pelayanan kesehatan adalah pasien dibawa ke unit gawat darurat oleh keluarga atau orang lain setelah melakukan percobaan bunuh diri, yang kedua adalah ketika pasien dilakukan anamnesis dan ditemukan kecenderungan bunuh diri (Wulandari et al., 2014).

Faktor yang mengaruhi kejadian bunuh diri bukan hanya terkait aspek psikologis saja melainkan faktor sosial juga dapat menjadi pemicu bunuh diri (Bachmann, 2018), masalah depresi juga sangat lazim sumber literature menggunakan data base yang relevan yaitu PubMed, Science Direct dan Search Engine Google Scholar dengan menggunakan kata kunci: suicide prevention, suicide intervention, suicide therapy, suicide treatment dan Suicide. Pencarian literatur mulai tahun 2016 sampai 2 november 2020, kriteria inklusi literatur yang dimasukkan: 1). Bahasa Inggris 2). Menggunakan metode Randomized Controlled Trial (RCT) 3). Terdapat data dikaitkan dengan berbagai hasil negatif, termasuk bunuh diri (Sander et al., 2020). Terapi farmakologis, psikologis, pendidikan kesehatan, dukungan keluarga maupun sosial media diusulkan sebagai tindakan yang efektif untuk mengatasi depresi dan bunuh diri ( $\mathrm{Na}$ et al., 2020), Namun pedoman tersebut tidak memiliki cukup bukti dalam pencegahan bunuh diri, sehingga untuk menemukan manajemen yang ideal dalam mencegah bunuh diri menjadi tantangan tersendiri.

Untuk itu tujuan literature review ini ingin melihat intervensi apa saja yang dapat dilakukan dalam mencegah kejadian bunuh diri dan juga melihat seberapa besar efek intervensi tersebut dalam mencegah kejadian bunuh diri. Untuk menjawab pertanyaan ini sebuah upaya dilakukan untuk meninjau dan merangkum secara sistematis hasil studi yang dipublikasikan mengenai efektivitas intervensi dalam mencegah kejadian bunuh diri.

Dengan adanya update informasi tentang intervensi pencegahan bunuh diri diharapkan dapat diaplikasikan dan dikembangkan dengan penelitian lebih mendalam guna mencegah tingginya kematian karena bunuh diri dan peningkatan sistem pelayanan kesehatan.

\section{METODE PENELITIAN}

Tujuan penulisan ini untuk melakukan review pada penelitian yang dipublikasikan mengenai pengaruh suatu intervensi dalam pencegahan tindakan bunuh diri. Pencarian

sebelum dan sesudah intervensi 4). Artikel dengan bentuk full text.

\section{HASIL}

Hasil pencarian data base melalui PubMed, Science Direct dan Search Engine Google Scholar dengan kata kunci ditemukan 998 artikel penelitian, kemudian dilakukan skrining ditemukan 193 artikel. Selanjutnya diseleksi melalui abstrak didapatkan 41 artikel. Tahap akhir dengan seleksi kriteria inklusi didapatkan 9 artikel untuk dilakukan review (Gambar 1). Penjelasan karakteristik mengenai artikel yang dimasukkan dalam review tercantum 
dalam tabel 1, yang meliputi penulis, ratarata umur, jumlah sampel, jenis intervensi, frekuensi, dan hasil penelitian

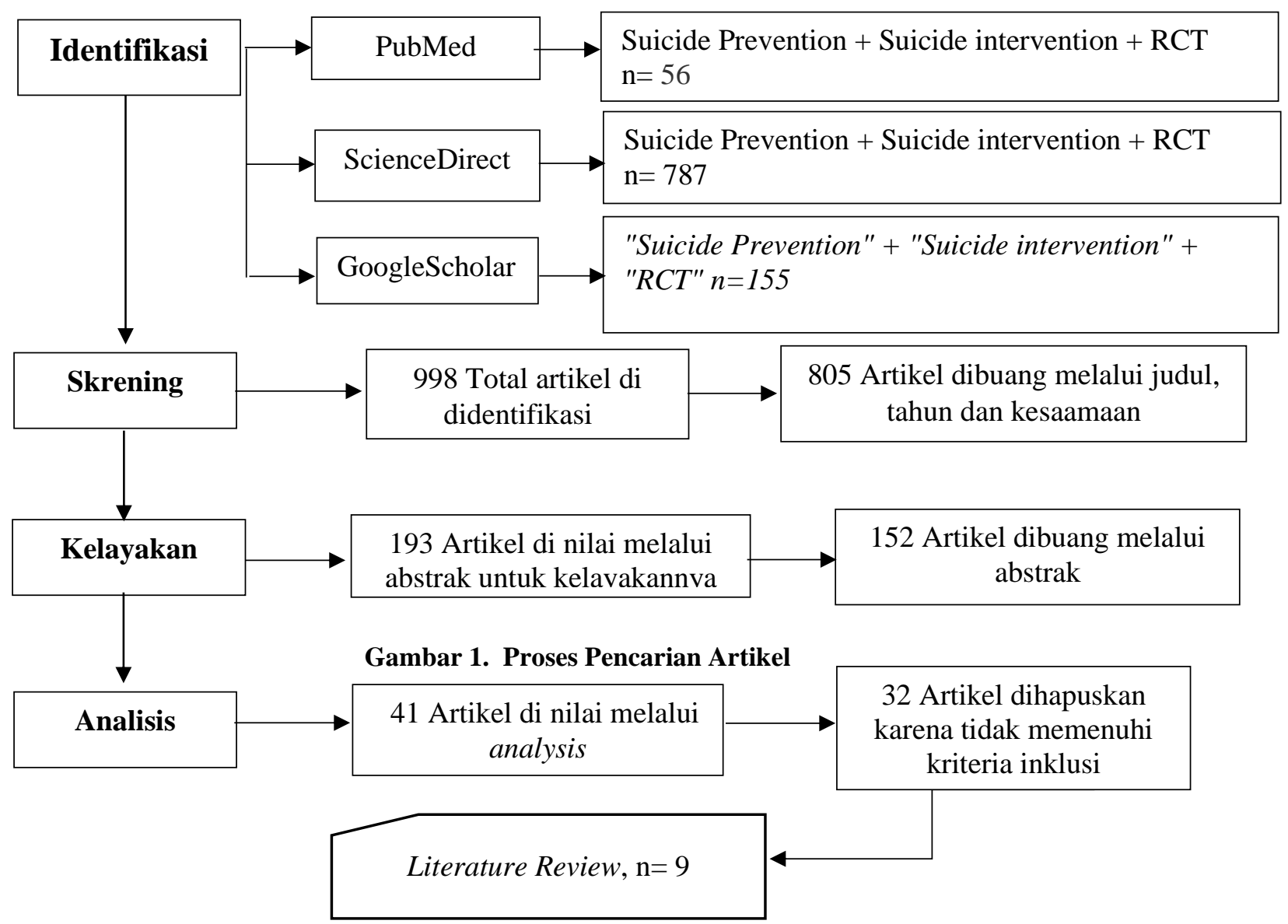


Tabel 1. Studi Karakteristik

\begin{tabular}{|c|c|c|c|c|c|c|}
\hline $\begin{array}{l}\text { Penulis, } \\
\text { tahun }\end{array}$ & $\begin{array}{c}\text { Rata- } \\
\text { rata } \\
\text { umur } \\
\text { (tahun) }\end{array}$ & $\begin{array}{c}\text { Desain } \\
\text { penelitian }\end{array}$ & Sampel & Intervensi & Frekuensi & Hasil \\
\hline $\begin{array}{l}\text { (Ducasse et al., } \\
\text { 2018) }\end{array}$ & 38 & $\begin{array}{l}\text { Randomized controlled } \\
\quad \text { trial }(R C T)\end{array}$ & 42 & $\begin{array}{c}\text { Acceptance and } \\
\text { Commitment } \\
\text { Therapy }(A C T) \\
\text { Vs } \\
\text { Relaxation (usually } \\
\text { treatment) }\end{array}$ & 7 minggu & $\begin{array}{l}\text { Perubahan terhadap suicidal ideation lebih } \\
\text { tinggi pada kelompok ACT dibandingkan } \\
\text { relaksasi ( } \mathrm{p}=0.03) \text {, perubahan juga terjadi pada } \\
\text { tanda gejala depresi, ansietas, nyeri psikologis, } \\
\text { keputusasaan, kemarahan dan kualitas hidup } \\
\text { ACT juga meningkatkan proses terapeutik dan } \\
\text { kepuasan terkait program. }\end{array}$ \\
\hline $\begin{array}{l}\text { (Asarnow et al., } \\
\text { 2015) }\end{array}$ & 14 & $\begin{array}{l}\text { Randomized controlled } \\
\text { trial }(R C T)\end{array}$ & 35 & $\begin{array}{l}\text { Cognitive- Behavioral } \\
\text { Treatment dengan Safe } \\
\text { Alternative for Teens } \\
\text { and Youths (SAFETY) }\end{array}$ & 12 minggu & $\begin{array}{l}\text { Menurunkan } 3 \% \text { selama } 3 \text { bulan dan } \\
\text { menurunkan } 6 \% \text { selama } 6 \text { bulan follow up dalam } \\
\text { percobaan bunuh diri }\end{array}$ \\
\hline $\begin{array}{l}\text { (McCauley et } \\
\text { al., 2018) }\end{array}$ & 15 & $\begin{array}{l}\text { Randomized controlled } \\
\text { trial }(R C T)\end{array}$ & 173 & $\begin{array}{l}\text { Dialectical Behaviour } \\
\text { Therapy }(\text { DBT }) \text { dan } \\
\text { Individual and Group } \\
\text { Supportive Therapy } \\
\text { (IGST) }\end{array}$ & 6 bulan & $\begin{array}{l}\text { DBT menurunkan upaya bunuh diri } 90,3 \% \text {, } \\
\text { tanpa cedera diri } 56,9 \% \text { dan melukai diri } 54,2 \% \text {. } \\
\text { Sedangkan IGST menurunkan menurunkan } \\
\text { upaya bunuh diri } 78,9 \% \text {, tanpa cedera diri } 40.0 \% \\
\text { dan melukai diri } 36,9 \% \text {. Sehingga pengobatan } \\
\text { DBT (75,6) lebih tinggi dibanding IGST } \\
(55,2 \%)\end{array}$ \\
\hline $\begin{array}{l}\text { (Asarnow et al., } \\
\text { 2017) }\end{array}$ & 15 & $\begin{array}{l}\text { Randomized controlled } \\
\text { trial }(R C T)\end{array}$ & 42 & $\begin{array}{c}\text { Safe Alternative for } \\
\text { Teens and Youths } \\
\text { (SAFETY) } \\
\text { VS } \\
\text { Education Accessing } \\
\text { Community Treatment } \\
\text { (treatment as } \\
\text { usual)(E-TAU) }\end{array}$ & 3 bulan & $\begin{array}{l}\text { SAFETY secara signifikan lebih tinggi dalam } \\
\text { bertahan hidup tanpa upaya bunuh diri } \\
\text { dibanding E-TAU }(p=0.02) \text { dan kelangsungan } \\
\text { kehidupan }(p=0.02)\end{array}$ \\
\hline $\begin{array}{l}\text { (Schilling et al., } \\
\text { 2016) }\end{array}$ & - & $\begin{array}{l}\text { Randomized controlled } \\
\text { trial }(R C T)\end{array}$ & 1046 & Sign of Suicide (SOS) & 3 bulan & $\begin{array}{l}\text { Intervensi program SOS secara signifikan } \\
\text { menurunkan } 64 \% \text { dalam upaya bunuh diri }\end{array}$ \\
\hline $\begin{array}{l}\text { (Grupp-Phelan } \\
\text { et al., 2019) }\end{array}$ & 15 & $\begin{array}{l}\text { Randomized controlled } \\
\text { trial }(R C T)\end{array}$ & 168 & $\begin{array}{l}\text { The suicidal teens } \\
\text { accessing treatment } \\
\text { after an emergency } \\
\text { visit (STAT-ED) }\end{array}$ & $\begin{array}{l}2 \text { bulan dan } 6 \\
\text { bulan }\end{array}$ & $\begin{array}{l}\text { Tidak ada perbedaan yang signifikan dalam hal } \\
\text { ide bunuh diri }(\mathrm{p}=0.72) \text { dan gejala depresi }(\mathrm{p}= \\
0.60) \text {. Tetapi selama } 6 \text { bulan STAT_ED } \\
\text { memiliki tingkat inisiasi perawatan kesehatan }\end{array}$ \\
\hline
\end{tabular}




\begin{tabular}{|c|c|c|c|c|c|c|}
\hline & & & & $\begin{array}{c}\text { (motivational } \\
\text { interviewing } \\
V s \\
\text { enhance usual care } \\
\text { (EUC) }\end{array}$ & & $\begin{array}{l}\text { mental lebih tinggi dan lebih banyak janji temu } \\
(\mathrm{p}=0,01)\end{array}$ \\
\hline $\begin{array}{l}\text { (Ducasse et al., } \\
\text { 2019) }\end{array}$ & 42 & $\begin{array}{l}\text { Randomized controlled } \\
\text { trial }(R C T)\end{array}$ & 2001 & $\begin{array}{l}\text { Gratitude diary vs } \\
\quad \text { food diary }\end{array}$ & 7 hari & $\begin{array}{l}\text { Tidak terdapat perbedaan perubahan signifikan } \\
\text { pada kedua kelompok mengenai intensitas ide } \\
\text { bunuh diri dan keputusasaan. Terdapat } \\
\text { perubahan pada kedua kelompok mengenai } \\
\text { nyeri psikologis }(\mathrm{p}=0.05) \text {. Rata-rata perubahan } \\
\text { depresi, kecemasan dan optimisme signifikan } \\
\text { lebih tinggi pada kelompok intervensi. }\end{array}$ \\
\hline $\begin{array}{l}\text { (Michel et al., } \\
\text { 2017) }\end{array}$ & - & $\begin{array}{l}\text { Randomized controlled } \\
\text { trial }(R C T)\end{array}$ & 120 & \begin{tabular}{l}
\multicolumn{1}{c}{ Usual care } \\
$\quad$ Vs \\
Attempted suicide \\
short intervention \\
program) ASSIP
\end{tabular} & 24 Bulan & $\begin{array}{l}\text { ASSIP lebih efektif dalam mencegah resiko } \\
\text { bunuh diri sebesar } 80 \%(p=0.0001)\end{array}$ \\
\hline $\begin{array}{l}\text { (Luxton et al., } \\
\text { 2020) }\end{array}$ & 33 & $\begin{array}{l}\text { Randomized controlled } \\
\text { trial }(R C T)\end{array}$ & 1318 & $\begin{array}{l}\text { Caring later } \\
\text { Vs } \\
\text { Usual care }\end{array}$ & 2 tahun & $\begin{array}{l}\text { Tidak ada perbedaan yang signifikan antara dua } \\
\text { kelompok dalam pelaporan kejadian bunuh diri } \\
\text { dan yang berhubungan dengan resiko bunuh diri }\end{array}$ \\
\hline
\end{tabular}




\section{Karakteristik Metode}

A. Tipe Intervensi

Berdasarkan tujuan penulisan terdapat sembilan studi yang memenuhi syarat untuk literature review dan teridentifikasi dari sembilan studi ditemukan delapan jenis intervensi yang digunakan dalam pencegahan bunuh diri, yaitu ACT (Ducasse et al., 2018), CBT SAFETY (Asarnow et al., 2015; Asarnow et al., 2017), DBT (McCauley et al., 2018), SOS (Schilling et al., 2016), STAT-ED (Grupp-Phelan et al., 2019), Gratitude diary (Ducasse et al., 2019), ASSIP (Michel et al., 2017) dan caring email (CL) (Luxton et al., 2020).

B. Frekuensi Pemberian intervensi

Intervensi pencegahan bunuh diri pada literature review diberikan dengan durasi yang berbeda-beda. Intervensi pemberian ACT dilakukan selama 7 minggu (Ducasse et al., 2018), intervensi CBT SAFETY dilakukan selama 12 minggu (Asarnow et al., 2015; Asarnow et al., 2017), intervensi DBT dilakukan selama 6 bulan (McCauley et al., 2018), intervensi SOS dilakukan selama 3 bulan (Schilling et al., 2016), intervensi STAT-ED dilakukan selama 2 bulan dan 6 bulan follow up (Grupp-Phelan et al., 2019), intervensi Gratitude diary dilakukan selama 7 hari (Ducasse et al., 2019), intervensi ASSIP dilakukan selama 24 bulan (Michel et al., 2017) dan intervensi caring email (CL) dilakukan selama 2 tahun (Luxton et al., 2020).

\section{Efek intervensi}

Intervensi pemberian ACT selama 7 minggu didapatkan hasil bahwa terdapat Perubahan terkait suicidal ideation lebih tinggi pada kelompok ACT dibandingkan relaksasi, perubahan juga terjadi pada tanda gejala depresi, ansietas, nyeri psikologis, keputusasaan, kemarahan dan kualitas hidup ACT juga meningkatkan proses terapeutik dan kepuasan terkait program (Ducasse et al., 2018).

Intervensi pemberian CBT dengan metode SAFETY dapat menurunkan percobaan bunuh diri sebesar 3\% selama 3 bulan dan menurunkan $6 \%$ selama 6 bulan follow up (Asarnow et al., 2015). Selain itu SAFETY secara signifikan lebih tinggi dalam bertahan hidup tanpa upaya bunuh diri dibanding E-TAU $(\mathrm{p}=0.02)$ dan kelangsungan kehidupan $(\mathrm{p}=0.02)$ (Asarnow et al., 2017).

Intervensi DBT selama 6 bulan menurunkan upaya bunuh diri 90,3\%, tanpa cedera diri 56,9 dan melukai diri 54,2\%. Sedangkan IGST menurunkan menurunkan upaya bunuh diri 78,9\%, tanpa cedera diri $40.0 \%$ dan melukai diri 36,9\%. Sehingga pengobatan DBT $(75,6)$ lebih tinggi dibanding IGST $(55,2 \%)$ (McCauley et al., 2018).

Pemberian intervensi SOS diketahui secara signifikan menurunkan $64 \%$ dalam upaya bunuh diri (Schilling et al., 2016). Sedangkan intervensi STAT-ED dilaporkan tidak memiliki perbedaan yang signifikan dalam hal ide bunuh diri dan gejala dari depresi, tetapi STAD-ED memiliki pengaruh dalam inisiasi perawatan mental lebih tinggi dan lebih kooperatif dalam melakukan janji temu (Grupp-Phelan et al., 2019).

Intervensi gratitude diary diketahui tidak memiliki perubahan yang signifikan mengenai intensitas ide bunuh diri dan keputusassan, akan tetapi terdapat perubahan pada kedua kelompok mengenai nyeri psikologis dengan rata-rata perubahan depresi, kecemasan dan optimisme (Ducasse et al., 2019).

Intervensi ASSIP diketahui $80 \%$ efektif dalam mencegah resiko bunuh diri (Michel et al., 2017). Sedangkan intervensi CL diketahui tidak signifikan dalam pelaporan kejadian bunuh diri dan yang berhubungan dengan resiko bunuh diri (Luxton et al., 2020).

\section{PEMBAHASAN}

Beberapa penelitian sudah dilakukan untuk mengetahui pengaruh berbagai intervensi dalam mencegah bunuh diri. Berdasarkan data tabel 1 dapat dijelaskan bahwa intervensi yang dapat diberikan ACT, CBT SAFETY, DBT, SOS, STATED, Gratitude diary, ASSIP dan Caring email (CL). Dari beberapa intervensi tersebut ACT, CBT, SAFETY, SOS, ASSIP menunjukan adanya perubahan dalam menurunkan bunuh diri, sedangkan intervensi gratitude dairy tidak memiliki efek yang signifikan walaupun terjadi 
perubahan pada depresi, kecemasan dan optimisme. Sedangkan intervensi CL dilaporkan tidak memiliki efek yang signifikan.

Pendekatan secara humanistik, peningkatan hubungan antar pribadi dengan tidak mengurangi budaya manajeman resiko serta menciptakan layanan yang cukup untuk memenuhi kebutuhan orang-orang yang memiliki niat untuk bunuh diri, bekerja sama secara tulus dengan mereka yang memiliki pengalaman bunuh diri merupakan intervensi yang dapat dilakukan (Fitzpatrick \& River, 2018)

Pemberian intervensi juga ditemukan pada literature review ini memiliki frekuensi yang berbeda-beda, berdasarkan tabel 1 dijelaskan bahwa intervensi diketahui minimal 7 hari dan maksimal 2 tahun. Pemberian intervensi yang 7 hari diketahui tidak signifikan dalam penurunan resiko bunuh diri (Ducasse et al., 2019), sedangkan intervensi 2 tahun juga diketahui tidak memiliki efek yang signifikan (Luxton et al., 2020).

Sehingga bisa disimpukkan bahwa jenis intervensi yang memiliki kontribusi terbesar dalam penurunan resiko bunuh diri. Intervensi yang memberikan penyadaran terkait ide bunuh diri dan keikutsertaan keluarga merupakan intervensi yang direkomendasikan (Niederkrotenthaler \& Till, 2020) intervensi juga harus mengatasi perasaan tertekan, perencanaan keselamatan, regulasi dan penerimaan emosional, mengatasi pikiran untuk bunuh diri dan mengatasi bersosialisasi dengan orang lain (Larsen et al., 2017).

Sedangkan untuk resiko bunuh diri pada anak dapat dilakukan dengan meningkatkan hubungan keluarga dan keterampilan orang tua dalam mengatasi masalah anak (Weinstein et al., 2018). Selain itu faktor keikutsertaan atau intensitas pertemuan terhadap pelayanan kesehatan memiiki manfaat terkait ide bunuh diri dan juga perilaku bunuh diri (Blades et al., 2018). Aspek lain seperti konten dari intervensi juga berpengaruh, tiga aspek yang harus ada ditingkatkan meliputi pendidikan dan pengetahuan bunuh diri, penilaian bunuh diri dan keterampilan dalam mengatasi bunuh diri (Xue et al., 2020).

Hasil literature review ini mengidentifikasi delapan jenis intervensi yang dapat dilakukan dalam mencegah bunuh diri yaitu ACT, CBT, SAFETY, SOS, ASSIP. Untuk mengkonfirmasi semua data tersebut harus dilakukan penelitian lebih lanjut dengan memberikan data yang relevan sehingga kedepannya sebuah penelitian harus dilakukan dengan jenis intervensi yang mengandung pendidikan, pengetahuan dan keterampilan dalam mengatasi bunuh diri.

\section{KESIMPULAN}

Intervensi ACT, CBT, SAFETY, SOS, ASSIP dapat dilakukan untuk mencegah kejadian bunuh diri, dengan meningkatkan pengetahuan, pendidikan, ketarampilan mengenai bunuh diri dan penyadaran penuh terkait bunuh diri serta keikutsertaan keluarga merupakan pokok dari intervensi yang harus dilakukan guna mencegah bunuh diri.

\section{DAFTAR PUSTAKA}

Asarnow, J. R., Berk, M., Hughes, J. L., \& Anderson, N. L. (2015). The SAFETY Program: A Treatment-Development Trial of a Cognitive-Behavioral Family Treatment for Adolescent Suicide Attempters. Journal of Clinical Child and Adolescent Psychology, 44(1), 194-203. https://doi.org/10.1080/15374416.2014.9 40624

Asarnow, J. R., Hughes, J. L., Babeva, K. N., \& Sugar, C. A. (2017). CognitiveBehavioral Family Treatment for Suicide Attempt Prevention: A Randomized Controlled Trial. Journal of the American Academy of Child and Adolescent Psychiatry, 56(6), 506-514. https://doi.org/10.1016/j.jaac.2017.03.01 5

Bachmann, S. (2018). Epidemiology of suicide and the psychiatric perspective. International Journal of Environmental Research and Public Health, 15(7), 1-23. https://doi.org/10.3390/ijerph15071425

Blades, C. A., Stritzke, W. G. K., Page, A. C., \& Brown, J. D. (2018). The benefits and risks of asking research participants 
about suicide: A meta-analysis of the impact of exposure to suicide-related content. Clinical Psychology Review, 64, $1-12$.

https://doi.org/10.1016/j.cpr.2018.07.00 1

Ducasse, D., Dassa, D., Courtet, P., BrandArpon, V., Walter, A., Guillaume, S., Jaussent, I., \& Olié, E. (2019). Gratitude diary for the management of suicidal inpatients: A randomized controlled trial. Depression and Anxiety, 36(5), 400-411. https://doi.org/10.1002/da.22877

Ducasse, D., Jaussent, I., Arpon-Brand, V., Vienot, M., Laglaoui, C., Béziat, S., Calati, R., Carrière, I., Guillaume, S., Courtet, P., \& Olié, E. (2018). Acceptance and commitment therapy for the management of suicidal patients: A randomized controlled trial. Psychotherapy and Psychosomatics, 87(4), 211-222. https://doi.org/10.1159/000488715

Fitzpatrick, S. J., \& River, J. (2018). Beyond the Medical Model: Future Directions for Suicide Intervention Services. International Journal of Health Services, 48(1), 189-203. https://doi.org/10.1177/00207314177160 86

Grupp-Phelan, J., Stevens, J., Boyd, S., Cohen, D. M., Ammerman, R. T., LiddyHicks, S., Heck, K., Marcus, S. C., Stone, L., Campo, J. V., \& Bridge, J. A. (2019). Effect of a Motivational InterviewingBased Intervention on Initiation of Mental Health Treatment and Mental Health After an Emergency Department Visit Among Suicidal Adolescents: A Randomized Clinical Trial. JAMA Network Open, 2(12), e1917941. https://doi.org/10.1001/jamanetworkope n.2019.17941

Larsen, M. E., Shand, F., Morley, K., Batterham, P. J., Petrie, K., Reda, B., Berrouiguet, S., Haber, P. S., Carter, G., \& Christensen, H. (2017). A Mobile Text Message Intervention to Reduce Repeat Suicidal Episodes: Design and Development of Reconnecting After a Suicide Attempt (RAFT). JMIR Mental Health, 4(4), e56. https://doi.org/10.2196/mental.7500

Luxton, D. D., Smolenski, D. J., Reger, M. A., Relova, R. M. V., \& Skopp, N. A. (2020). Caring E-mails for Military and Veteran Suicide Prevention: A Randomized Controlled Trial. Suicide and Life-Threatening Behavior, 50(1), 300-314.

https://doi.org/10.1111/sltb.12589

McCauley, E., Berk, M. S., Asarnow, J. R., Adrian, M., Cohen, J., Korslund, K., Avina, C., Hughes, J., Harned, M., Gallop, R., \& Linehan, M. M. (2018). Efficacy of dialectical behavior therapy for adolescents at high risk for suicide a randomized clinical trial. JAMA Psychiatry, 75(8), 777-785. https://doi.org/10.1001/jamapsychiatry.2 018.1109

Michel, K., Valach, L., \& Gysin-Maillart, A. (2017). A novel therapy for people who attempt suicide and why we need new models of suicide. International Journal of Environmental Research and Public Health, 14(3). https://doi.org/10.3390/ijerph14030243

Mulyani, A. A., \& Eridiana, W. (2019). Faktor-Faktor Yang Melatarbelakangi Fenomena Bunuh Diri Di Gunungkidul. Sosietas, 8(2), 510-516. https://doi.org/10.17509/sosietas.v8i2.14 593

Na, K. S., Park, S. C., Kwon, S. J., Kim, M., Kim, H. J., Baik, M., Seol, J., An, E. J., Lee, S. M., Lee, E. J., Lim, M., Cho, S. J., Kim, G. H., Kim, N., Jeon, H. J., Paik, J. W., Oh, K. S., \& Lee, H. Y. (2020). Contents of the standardized suicide prevention program for gatekeeper intervention in Korea, version 2.0. Psychiatry Investigation, 17(11), 11491157.

https://doi.org/10.30773/pi.2020.0271

Niederkrotenthaler, T., \& Till, B. (2020). Effects of suicide awareness materials on individuals with recent suicidal ideation or attempt: online randomised controlled trial. The British Journal of Psychiatry, 217(6), 693-700. https://doi.org/10.1192/bjp.2019.259

Pusat Data dan Informasi Kementrian Kesehatan Republik Indonesia. (2019). 
Situasi dan Pencegahan Bunuh Diri (pp. $1-10)$.

Robinson, J., Cox, G., Bailey, E., Hetrick, S., Rodrigues, M., Fisher, S., \& Herrman, H. (2016). Social media and suicide prevention: A systematic review. Early Intervention in Psychiatry, 10(2), 103121. https://doi.org/10.1111/eip.12229

Sander, L., Gerhardinger, K., Bailey, E., Robinson, J., Lin, J., Cuijpers, P., \& Mühlmann, C. (2020). Suicide risk management in research on internetbased interventions for depression: A synthesis of the current state and recommendations for future research. Journal of Affective Disorders, 263, 676683.

https://doi.org/10.1016/j.jad.2019.11.045

Schilling, E. A., Aseltine, R. H., \& James, A. (2016). The SOS suicide prevention program: Further evidence of efficacy and effectiveness. Prevention Science, 17(2), 157-166. https://doi.org/10.1007/s11121-0150594-3

Sheng, K., Zhang, P., Chen, L., Cheng, J., Wu, C., \& Chen, J. (2014). Intradialytic exercise in hemodialysis patients: A systematic review and meta-analysis. American Journal of Nephrology, 40(5),
478-490.

https://doi.org/10.1159/000368722

Weinstein, S. M., Cruz, R. A., Isaia, A. R., Peters, A. T., \& West, A. E. (2018). Child- and Family-Focused Cognitive Behavioral Therapy for Pediatric Bipolar Disorder: Applications for Suicide Prevention. Suicide and Life-Threatening Behavior, 48(6), 797-811. https://doi.org/10.1111/sltb.12416

World Health Organization. (2019). Suicide in the world: Global Health Estimates. World Health Organization, Geneva, 32.

Wulandari, I. S., Ratnawati, R., Supriyati, L., \& Kumboyono. (2014). Pengalaman Perawat Instalasi Gawat Darurat dalam Merawat Pasien Percobaan Bunuh Diri di Rumah Sakit Dr. Moewardi Surakarta. Jurnal KesMaDaSka, 10.

Xue, C., Yang, Y., Xu, K., Shi, X., \& Liu, H. (2020). Health personnel-targeted education interventions on inpatient suicide prevention in general hospitals: A scoping review. International Journal of Nursing Sciences, 7(4), 477-483. https://doi.org/10.1016/j.ijnss.2020.09.0 06 